\title{
Basic Characteristics of In-Wheel Magnetic-Geared Motors
}

\author{
Kenji Nakamura, Kazuki Akimoto, Toshiaki Takemae, and Osamu Ichinokura \\ Graduate School of Engineering, Tohoku University, 6-6-05 Aoba Aramaki, Aoba-ku, Sendai 980-8579, Japan
}

\begin{abstract}
This paper presents a feasibility study of an in-wheel magnetic-geared motor for walking support machines. The proposed magnetic-geared motor consists of an axial-gap permanent magnet (PM) motor and a magnetic gear. Axial-gap PM motors generally have larger torque than conventional radial-gap motors when their structures are flat like those in in-wheel motors. Moreover, the axial-gap PM motor was combined with magnetic gears since the in-wheel motor requires further large torque at low speed. The characteristics and usefulness of the proposed magnetic-geared motor are demonstrated through experiments and analysis conducted using finite element method (FEM).
\end{abstract}

Key words: magnetic-geared motor, in-wheel, axial-gap, walking support machines

\section{Introduction}

In Japan, aging population and lower birthrate are rapidly progressing in comparison with other developed countries. According to "Population Projections for Japan" published by National Institute of Population and Social Security Research ${ }^{1)}$, it is expected that total population of our country will decrease, while elderly age population (65 years or older) will increase. The ratio of the elderly age population will be more than $35 \%$ after approximately 40 years. This means that one third or more will be over 65 years old in the near future. Therefore, it is one of the important tasks of our country to reduce physical burden in daily life of elderly persons.

The daily life supports include housework support, going out support, etc. Among them, the going out support by a walking support machine is expected to have an important role so that the elderly persons independently go out by their own will, which sustains and encourages the elderly persons to connect with a local community. Furthermore, a motor-assisted walking support machine can further expand an active range of the elderly persons since it has high carrying and hill climbing abilities. However, there is a problem of large weight and small luggage space due to the motor.

To resolve the above issue, we have employed an in-wheel motor that a motor mounted inside a wheel. The in-wheel motor requires a flat structure, light weight, and large torque at low speed. Therefore, we propose an axial-gap magnetic-geared motor as the in-wheel motor. The proposed magnetic-geared motor consists of an axial-gap permanent magnet (PM) motor and magnetic gear, which are mechanically combined.

The axial-gap PM motor has larger torque than a conventional radial-gap one, if its structure must be flat 2). The magnetic gear can regulate torque and speed as desired. Various types of magnetic gears have been introduced in previous papers ${ }^{3)-6}$. Among them, a flux-modulated magnetic gear has recently attracted interest since its torque density is higher than other magnetic gears 3), 4). Moreover, its efficiency is comparable to conventional mechanical gears ${ }^{6)-8}$. Hence, the desired large torque at low speed can be obtained by combining the axial-gap PM motor with the flux-modulated magnetic gear.

This paper presents feasibility study of the in-wheel magnetic-geared motor for walking support machines. Characteristics and usefulness of the proposed magnetic-geared motor are demonstrated by experiments and finite element method (FEM).

\section{Operating principle of the magnetic gear}

Fig. 1 illustrates a basic configuration of an axial-gap magnetic gear. It has two permanent magnet rotors, and ferromagnetic pole-pieces placed between the rotors. The upper side rotor is high speed and small torque one, and the lower side rotor is low speed and large torque one, respectively.

Fig. 2 shows a schematic diagram of gap flux distribution produced by the upper side rotor and the pole-pieces. If magnetomotive force (MMF) distribution of the permanent magnet is sinusoidal, it is given by

$$
f_{h}(\theta, t)=F_{a h} \cos \left\{p_{h}\left(\theta-\omega_{h} t\right)\right\}
$$

where the amplitude of the MMF is $F_{a h}$, the pole-pair number of the upper side rotor is $p_{h}$, and the angular velocity of the upper side rotor is $\omega_{h}$, respectively.

If permeance distribution of the pole-pieces is also sinusoidal, it is expressed by

$$
P(\theta)=\lambda_{d}+\lambda_{a} \cos \left(n_{\mathrm{s}} \theta\right)
$$

where the mean value of the permeance is $\lambda_{d}$, the

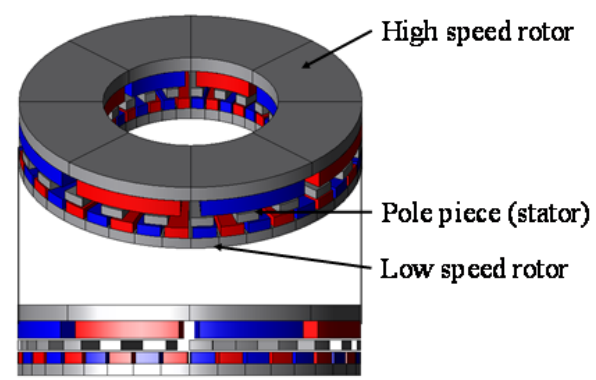

Fig. 1 Basic configuration of axial-gap magnetic gear. 


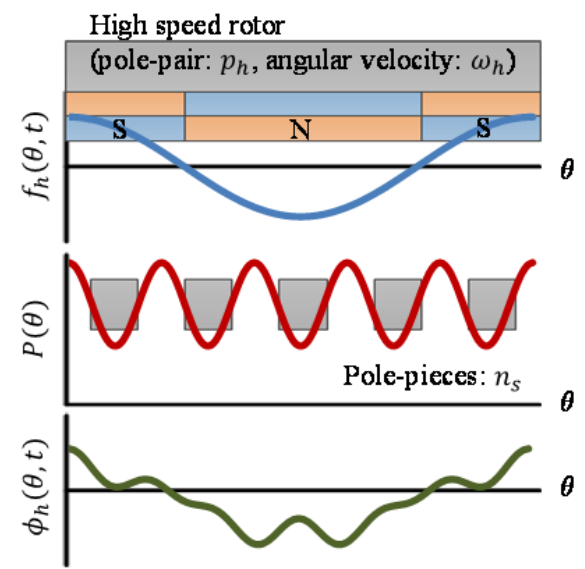

Fig. 2 Schematic of gap flux distribution produced by upper side rotor and pole-pieces.

variation component is $\lambda_{a}$, and the pole number of the pole-pieces is $n_{s}$, respectively.

Accordingly, as the product of the $\operatorname{MMF} f_{h}(\theta, t)$ and the permeance $P(\theta)$, the gap flux distribution is obtained as follows:

$$
\begin{aligned}
\phi_{h}(\theta, t)= & F_{a h} \lambda_{d} \cos \left\{p_{h}\left(\theta-\omega_{h} t\right)\right\} \\
& +\frac{1}{2} F_{a h} \lambda_{a} \cos \left\{\left(n_{\mathrm{s}}+p_{h}\right)\left(\theta-\frac{p_{h}}{n_{\mathrm{s}}+p_{h}} \omega_{h} t\right)\right\} \\
& +\frac{1}{2} F_{a h} \lambda_{a} \cos \left\{\left(n_{\mathrm{s}}-p_{h}\right)\left(\theta-\frac{-p_{h}}{n_{\mathrm{s}}-p_{h}} \omega_{h} t\right)\right\}
\end{aligned}
$$

From (3), it is understood that the gap flux has two modulated-components $\left(n_{s}+p_{h}\right)$ and $\left(n_{s}-p_{h}\right)$ in addition to the normal component $p_{h}$ caused by the upper side rotor. The rotational speeds of these modulated components are $p_{h} \omega_{h} /\left(n_{s}+p_{h}\right)$ and $-p_{h} \omega_{h} /\left(n_{s}-p_{h}\right)$, respectively. Therefore, if the pole-pair number of the lower side rotor $p_{l}$ is set to $\left(n_{s}+p_{h}\right)$ or $\left(n_{s}-p_{h}\right)$, the lower side rotor rotates with the speed as follows:

$$
\omega_{l}= \pm \frac{p_{h} \omega_{h}}{\left(n_{s} \pm p_{h}\right)}= \pm \frac{p_{h}}{p_{l}} \omega_{h} .
$$

It is clear from (4) that the gear ratio of the magnetic gear is simply determined by the ratio of the pole-pair numbers of the upper and lower side rotors.

In (3), the amplitudes of the $\left(n_{s}+p_{h}\right)$ and $\left(n_{s}-p_{h}\right)$ components are the same, but actually the $\left(n_{s}-p_{h}\right)$ component is larger than the $\left(n_{s}+p_{h}\right)$ one, since the actual distributions of the MMF and the permeance are approximately square wave not sinusoidal. Hence, the pole-pair number of the lower side rotor is set as $p_{l}=n_{s}-$ $p_{h}$, and the speed ratio is given by

$$
\frac{\omega_{l}}{\omega_{h}}=-\frac{p_{h}}{p_{l}}
$$

On the other hand, when the lower side rotor is fixed, the pole-pieces work as an output rotor instead of the lower side rotor. In this case, the speed ratio of the upper side rotor and the pole-pieces rotor is given by

$$
\frac{\omega_{s}}{\omega_{h}}=\frac{p_{h}}{n_{s}}
$$

3. Calculation of basic characteristics of the magnetic-geared motor

\subsection{Basic configuration of the magnetic-geared motor}

Fig. 3 indicates a basic configuration of an axial-gap magnetic-geared motor used in the consideration. As shown in the figure, the PM rotor works as both a motor output rotor and a gear input rotor.

The motor part is composed of the 12 -slots stator with three-phase concentrated windings and the 4-pole-pairs PM rotor. The core material is non-oriented $\mathrm{Si}$ steel with a thickness of $0.35 \mathrm{~mm}$. The rotor magnet is sintered Nd-Fe-B.

The gear part is consists of the 4-pole-pairs PM rotor, the 19-pole-pairs PM stator, and the 23-poles pole-pieces (PP) rotor. The material of the PP rotor is soft magnetic composite and the magnet materials are sintered $\mathrm{Nd}-\mathrm{Fe}-\mathrm{B}$.

When three-phase sinusoidal current flows into the stator windings, the PM rotor synchronously rotates with the rotating magnetic field. Then, mechanical output can be obtained from the PP rotor of which the speed is reduced by the gear ratio of $5.75(=23 / 4)$.

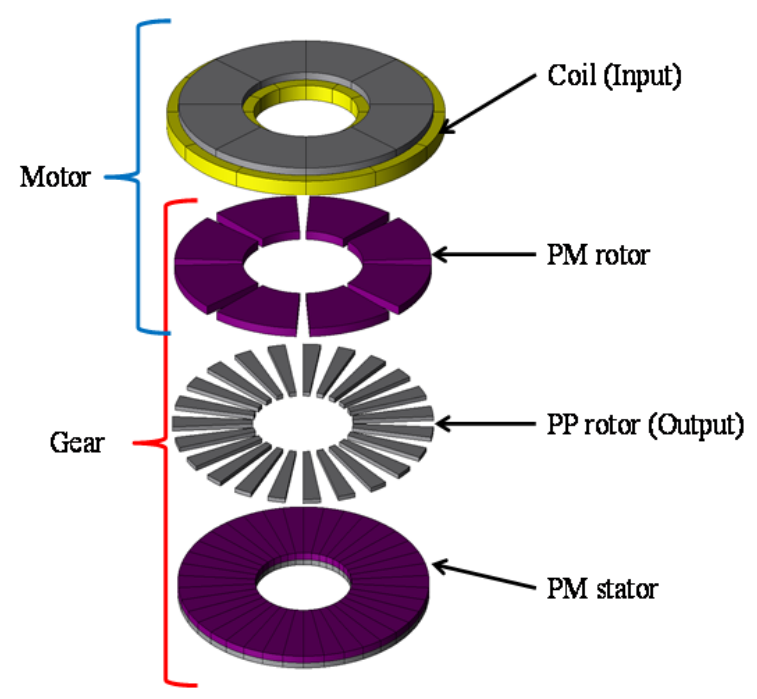

(a) Exploded view

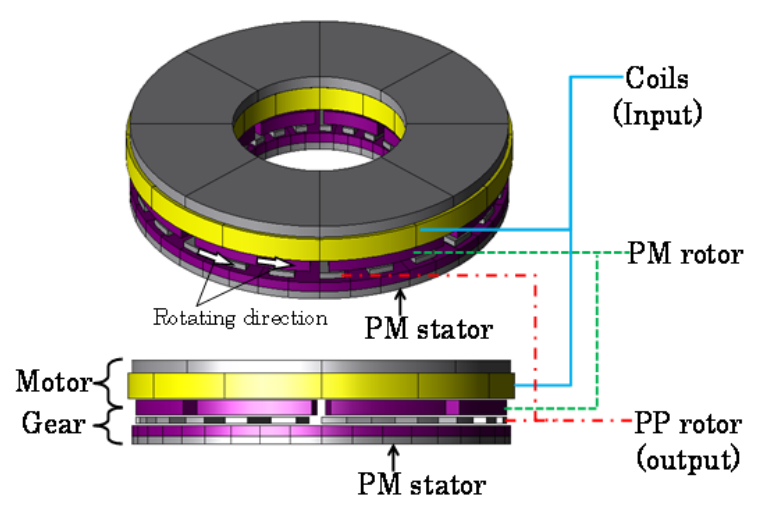

(b) Assembled view

Fig. 3 Basic configuration of axial-gap magnetic-geared motor. 


\subsection{Calculated characteristics of the magnetic-geared motor}

Table 1 indicates required specifications for the in-wheel motor of a certain walking support machine which is currently under joint development with a company. The torques shown in the table are the required values per one motor, and the required torque at $25 \%$ incline is to ride over a step on the road.

Table 2 shows specifications of the designed axial-gap magnetic-geared motor. The motor diameter is $100 \mathrm{~mm}$, and the axial length is $20 \mathrm{~mm}$. The lengths of three air-gaps are $0.5 \mathrm{~mm}$ each.

Table 1 Required specifications for the in-wheel motor of a walking support machine.

\begin{tabular}{|c|c|}
\hline Diameter (include housing) & $110 \mathrm{~mm}$ \\
\hline Axial length (include housing) & $27 \mathrm{~mm}$ \\
\hline Rated speed & $125.3 \mathrm{rpm}$ \\
\hline Supply voltage & DC $12 \mathrm{~V}$ \\
\hline \multicolumn{2}{|l|}{ Required torque } \\
\hline Flat ground & $0.47 \mathrm{~N} \cdot \mathrm{m}$ \\
\hline $5 \%$ incline & $\begin{array}{l}0.93 \mathrm{~N} \cdot \mathrm{m} \\
\left(\text { under } 5 \mathrm{~A} / \mathrm{mm}^{2} \text { ) }\right.\end{array}$ \\
\hline $25 \%$ incline & $\begin{array}{l}2.73 \mathrm{~N} \cdot \mathrm{m} \\
\left(\text { under } 10 \mathrm{~A} / \mathrm{mm}^{2} \text { ) }\right.\end{array}$ \\
\hline
\end{tabular}

Table 2 Specifications for the designed axial-gap magnetic-geared motor.

\begin{tabular}{|l|l|}
\hline Diameter & $100 \mathrm{~mm}$ \\
\hline Axial length & $20 \mathrm{~mm}$ \\
\hline Rotational speed (PM rotor) & $690 \mathrm{rpm}$ \\
\hline Rotational speed (PP rotor) & $120 \mathrm{rpm}$ \\
\hline Number of turns/pole & 67 turns \\
\hline Pole-pairs of the PM rotor & 4 \\
\hline Pole-pairs of the PM stator & 19 \\
\hline Pole number of the PP rotor & 23 \\
\hline Gear ratio & 5.75 \\
\hline Gap length & 0.5 mm $\times 3$ \\
\hline Magnet material & Sintered Nd-Fe-B \\
\hline Material of the PP rotor & Soft magnetic composite \\
\hline Material of the stator core & Non-oriented Si steel \\
\hline
\end{tabular}

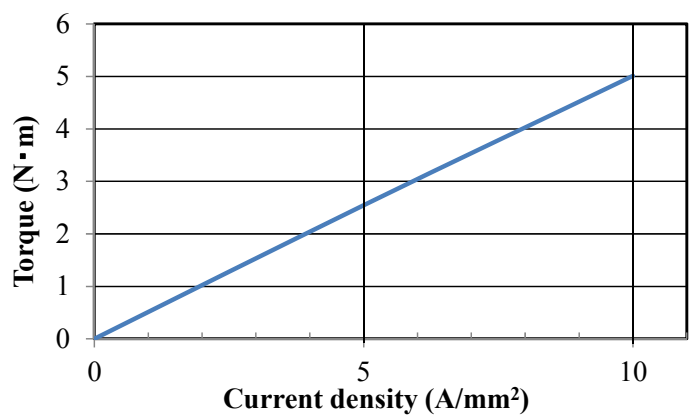

Fig. 4 Calculated torque characteristics of the axial-gap magnetic-geared motor.
Characteristics of the axial-gap magnetic-geared motor are calculated by three-dimensional FEM, since the motor has a three-dimensional structure. In the calculation, only copper loss is considered.

Fig. 4 shows calculated torque characteristics of the axial-gap magnetic-geared motor. It is clear that the obtained torque is sufficiently larger than the required torque of the in-wheel motor for the walking support machine shown in Table 1.

\section{Experimental results of the magnetic-geared motor}

Fig. 5 shows an external view of a trial axial-gap magnetic-geared motor. Fig. 6 indicates actual gap lengths of the trial magnetic-geared motor. Although the gap lengths shown in Fig. 4 were $0.5 \mathrm{~mm}$ each, the gap lengths of the trial machine were regulated due to assemble and allowance reasons.

Fig. 7 shows measured and calculated torque characteristics of the trial axial-gap magnetic- geared motor. The calculated values shown in the figure are obtained from the FEM simulation when the

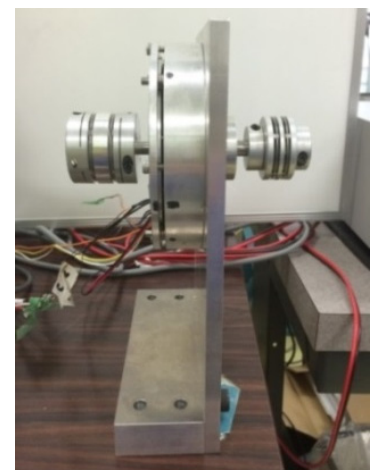

Fig. 5 Photograph of trial axial-gap magnetic-geared motor.

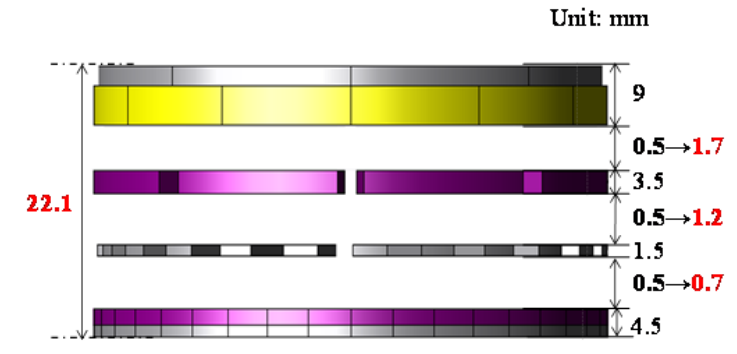

Fig. 6 Gap lengths of the trial magnetic-geared motor.

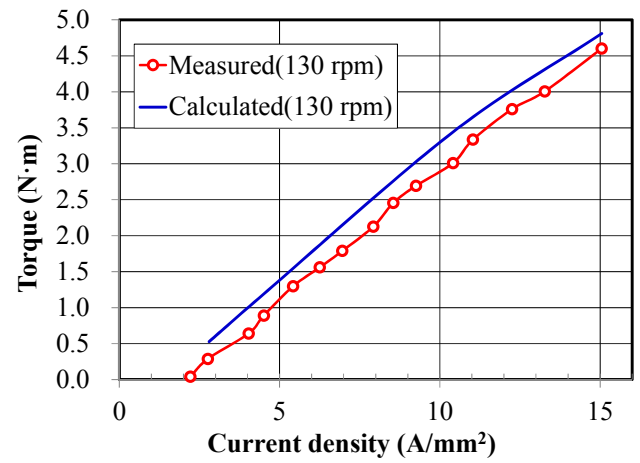

Fig. 7 Torque characteristics of the trial axial-gap magnetic-geared motor. 
magnetic-geared motor has the same gap lengths shown in Fig. 6. In addition, the measured three-phase current waveform is used as the input current of the simulation. The iron loss of the core, and eddy current in the magnets are taken into consideration in addition to the copper loss.

It is seen from the figure that the measured torque satisfies the required torque of $5 \%$ incline under 5 $\mathrm{A} / \mathrm{mm}^{2}$, and also exceeds the required torque of $25 \%$ incline under $10 \mathrm{~A} / \mathrm{mm}^{2}$, respectively.

Fig. 8 shows load characteristics of the trial axial-gap magnetic-geared motor. In the figure, the solid lines denote the measured values, and the broken lines indicate the calculated ones. The electrical input is $P_{i n}$. The mechanical output is $P_{\text {out }}$, which is obtained from the following equation:

$$
P_{\text {out }}=\omega_{s} \tau_{s}
$$

where the angular velocity of the PP rotor is $\omega_{s}$, and the torque of the $\mathrm{PP}$ rotor is $\tau_{s}$, respectively.

The calculated efficiency is obtained from

$$
\eta=\frac{P_{\text {out }}}{P_{\text {out }}+W_{c}+W_{i}+W_{e}} \times 100(\%),
$$

where the mechanical output is $P_{\text {out }}$, the copper loss is $W_{c}$, the iron loss of the stator, yoke, and pole-pieces is $W_{i}$, and the eddy current loss in the magnets is $W_{e}$, respectively. Hence, the calculated electrical input is given by $P_{\text {in }}=P_{\text {out }}+W_{c}+W_{i}+W_{e}$. The losses $W_{c}, W_{i}, W_{e}$ are individually calculated by the FEM simulation.

It is understood from the figure that the calculated and measured values are approximately in good agreement. The measured maximum efficiency is about $60 \%$. Further improvement of the efficiency is required in the future studies.

Fig. 9 indicates loss characteristics of the trial axial-gap magnetic-geared motor. In the figure, the solid lines show the measured values, and the broken lines denote the calculated ones. It is clear that the calculated copper loss almost agrees well with the measured one. On the other hand, the sum of the calculated iron loss and eddy current loss in the magnets $\left(W_{i}+W_{e}\right)$ are remarkably different from the measured values $\left(P_{i n}-\right.$ $\left.P_{\text {out }}-W_{c}\right)$. The reason is that the mechanical loss of the trial machine $W_{m}$ cannot be separated from the

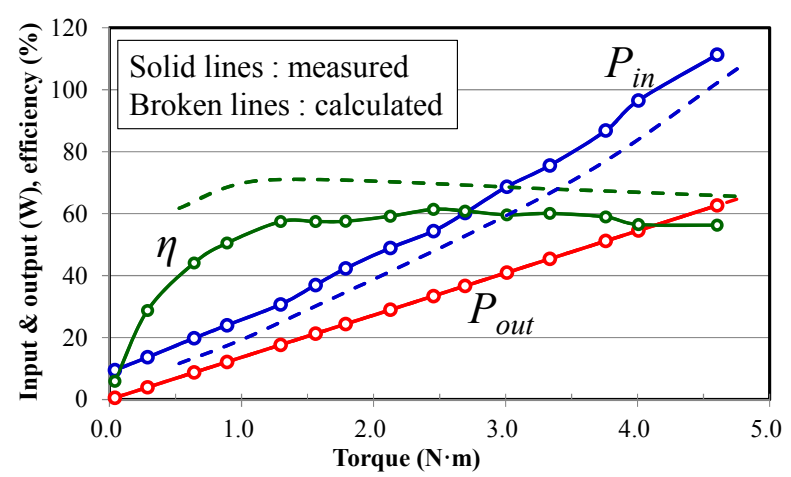

Fig. 8 Load characteristics of the trial axial-gap magnetic-geared motor.

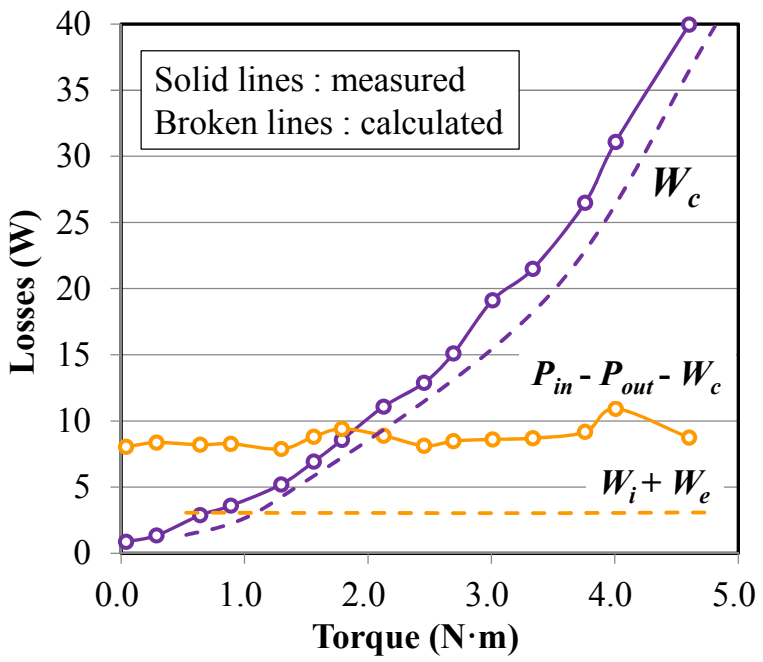

Fig. 9 Loss characteristics of the trial axial-gap magnetic-geared motor.

measured values. It is understood that the reduction of the copper loss and the mechanical loss is the most important to improve the efficiency of the trial magnetic-geared motor.

\section{Conclusion}

This paper presented the feasibility study of the in-wheel magnetic-geared motor for walking support machines. The proposed axial-gap magnetic-geared motor demonstrated that it has the sufficient torque as the in-wheel motor for walking support machines by experiments and FEM.

However, since the efficiency of the trial machine is not enough high, it is necessary to conduct further detailed investigation of the losses in the future studies.

Acknowledgements A part of this work was supported by JSPS KAKENHI Grant-in-Aid for Scientific Research (b), Grant Number 24360102.

\section{References}

1) “Population Projections for Japan (January 2012)", National Institute of Population and Social Security Research (2012).

2) T. Takemae, K. Nakamura, and O. Ichinokura, J. Magn. Soc. Jpn., 38, 15 (2013).

3) K. Atallah and D. Howe, IEEE Trans. Magn., 37, 2844 (2001).

4) K. Atallah, S. D. Calverley, and D. Howe, IEE Proc. Elect. Power Appl., 151, 135 (2004).

5) K. Tsurumoto, Y. Tanaka, and A. Kumagai, J. Magn. Soc. Jpn., 25, 1179 (2001).

6) K. Nakamura, M. Fukuoka, and O. Ichinokura, The 2013 Annual Meeting Record IEEJ, S19-6 (2013) (in Japanese).

7) M. Fukuoka, K. Nakamura, and O. Ichinokura, IEEJ Journal of Industry Applications, 3, 62 (2014).

8) K. Nakamura, M. Fukuoka, and O. Ichinokura, Journal of Applied Physics, 115, 17A314 (2014).

Received Oct. 22, 2014; Accepted Nov. 26, 2014 